Tropical Journal of Pharmaceutical Research October 2011; 10 (5): 631-635

(C) Pharmacotherapy Group,

Faculty of Pharmacy, University of Benin

Benin City, 300001 Nigeria.

All rights reserved.

Available online at http://www.tjpr.org

Research Article

http://dx.doi.org/10.4314/tjpr.v10i5.12

\title{
Readability of Malaria Medicine Information Leaflets in Nigeria
}

\author{
Asa Auta ${ }^{*}$ David Shalkur, Samuel B Banwat and Danlami W Dayom \\ Department of Clinical Pharmacy, University of Jos, Jos, Nigeria
}

\begin{abstract}
Purpose: To assess the readability of malaria medicines information leaflets available in Nigeria.

Methods: Fourty five leaflets were assessed using the Simplified Measure of Gobbledygook (SMOG) readability test and by examining them for paper type, font size type, use of symbols and pictograms, and bilingual information.

Results: The SMOG readability data revealed that the mean United State reading grade level for malaria medicines information leaflets available in Nigeria was $13.69 \pm 1.70$. This value is equivalent to a tertiary level of education in Nigeria. The study also revealed that $6.7 \%$ of the leaflets were glossy; $6.7 \%$ contained symbols and pictograms; $42.2 \%$ of the leaflets had a font type size < 8; and only $2.2 \%$ of the leaflets were produced in both English language and one of the major local languages of Nigeria.

Conclusion: Malaria medicine information leaflets available in the Nigerian market are not readable to the majority of the population. There is need for pharmaceutical companies to produce readable medicine information leaflets.
\end{abstract}

Keywords: Malaria, Medicine information leaflets, Readability, Simplified Measure of Gobbledygook. 


\section{INTRODUCTION}

Malaria is endemic in Nigeria, and accounts for most hospital visits [1]. It is one of the major causes of morbidity and mortality in Nigeria. About $50 \%$ of the population has at least one episode of malaria anually, with children under 5 having an average of $2-4$ attacks. It causes about 300,000 deaths anually, most of which are in children under the age of 5 [2].

Self-management of malaria is common in Nigeria [3]. About $70 \%$ of cases of malaria are managed at home [2]. However, studies have shown that home management of malaria is associated with inappropriate medicine use [2,4]. One of the strategies for the control of malaria in Nigeria is the provision of prompt and effective case management. This strategy is intended by the country's Federal Ministry of Health $(\mathrm{FMoH})$ to improve appropriate delivery of antimalarials at home and community levels [2]. Health promotion and behaviour change communication; and appropriate supply of good and quality artemisinin-based combination therapy (ACT) are key strategic components of the $\mathrm{FMoH}$ home management of malaria to improve appropriate selfmedication practices [2].

Although ACTs are designated in Nigeria as Prescription Only Medicines (POMs), they are frequently obtained without a prescription $[2,4]$. FMoH has initiated a process of rescheduling ACTs as over-the-counter (OTC) medicne to promote home management [2]. Therefore, appropriate medicine information is important to ensure their rational use at the community level. Readability is the relative ease with which a written prose conveys information [5]. Over 50 formulae have been developed to assess the readability of a document. These formulae often uses word length, sentence length, and polysyllabic frequency $[5,6]$. One of such formulae, Simplified Measure of Gobbledygook (SMOG), has been widely used in evaluating the readability of medicine information and has a reputation for reading level accuracy, simple directions, speed of use and for being a rigorous test for evaluating medicine information [7].

Readability of medicine information leaflets has been widely studied especially in countries where guidelines and regulations on readability and design of medicine information leaflets exist. In many of these studies, the readability of medicine information leaflets has been shown to be above the average reading grade level of the target population. Bradley et al [8] assessed the readability of over-the-counter medicine information leaflets available in the United Kingdom market and concluded that the mean reading grades obtained were above the mean reading age of the general adult population. Basara and Juergens [9] showed that the readability of the medicine information leaflets in the United State is above the suggested readability level of fifthto-seventh grade. Chubaty et al [10] demonstrated that most medicine leaflets intended for seniors in Canada, did not meet established guidelines. The readability of medicine information leaflets has also been studied in South Africa [11]. However, no study has assessed the readability of medicine information leaflets in Nigeria.

The objective of the present study was to assess the readability of malaria medicine information leaflets available in Nigeria.

\section{METHODS}

\section{Test samples}

Malaria medicine information leaflets were obtained from community pharmacies in Jos, Nigeria. Only leaflets in respect of antimalarials of artemisinin-based preparation and those registered by Nigeria's Nataional Agency for Food, Drug Administration and Control (NAFDAC) were included in the study. A total of 68 malaria medicine information leaflets were accessed, out of which 45 leaflets/inserts were randomly selected using a 'lottery' method. 


\section{Readability test}

The SMOG readability test, which measures the level of education required to understand a text was used for this study [7]. Data on number of sentences and polysyllabic words were entered into Microsoft Excel 2007 spread sheet containing the readability test formula to generate readability grade level for each leaflet.

\section{Other tests}

The leaflets were also examined for paper type, font type and size, use of symbols and pictograms and bilingual information. Font size was evaluated by comparing the font size of each leaflet with a printed document containing different theme fonts of size 8 . In this study, we considered a font size of 8 as the minimum acceptable font size that is easy to read. Font size 8 is also considered the absolute minimum acceptable font size for medicine leaflets in European countries [12].

\section{Statistical analysis}

Data were analysed using Statistical Package for Social Sciences (SPSS) version 16 software (SPSS Inc) to generate the mean and standard deviation of the leaflets' reading grade level as well as the frequencies and percentages for all variables. One-sample ttest between percentages was performed for each variable to determine if a significant difference existed between the values for each variable.

\section{RESULTS}

\section{SMOG readability test}

As Table 1 shows, the United States reading grade level for malaria medicine information leaflets available in Nigeria ranged from 9 16 , with a majority of the leaflets having a reading grade level of 14 . The mean grade level was 13.69 with a standard deviation of 1.70 .
Table 1: Malaria medicine information leaflets reading grade using the SMOG test

\begin{tabular}{llll}
\hline $\begin{array}{l}\text { SMOG } \\
\text { (US } \\
\text { grade } \\
\text { level) }\end{array}$ & $\begin{array}{l}\text { SMOG } \\
\text { (Nigerian } \\
\text { education level) }\end{array}$ & $\begin{array}{l}\text { No. of } \\
\text { leaflets } \\
\text { N, (\%) }\end{array}$ & $\begin{array}{l}\text { Cumu- } \\
\text { lative } \\
\text { (\%) }\end{array}$ \\
\hline 9 & Junior Secondary & $1(2.2)$ & 2.2 \\
10 & Senior Secondary & $1(2.2)$ & 4.4 \\
11 & Senior Secondary & $3(6.7)$ & 11.1 \\
12 & Senior Secondary & $6(13.3)$ & 24.4 \\
13 & Tertiary & $6(13.3)$ & 37.8 \\
14 & Tertiary & $12(26.7)$ & 64.4 \\
15 & Tertiary & $10(22.2)$ & 86.6 \\
16 & Tertiary & $6(13.3)$ & 100 \\
\hline
\end{tabular}

\section{Other tests}

The leaflets studied revealed that $6.7 \%$ of the leaflets were glossy; $57.8 \%$ of the leaflets had a font size $\geq 8 ; 6.7 \%$ contained symbols and pictograms; and only $2.2 \%$ of the leaflets were written in both English language and a major local language in Nigeria (Table 2).

Table 2: Other tests carried out to assess the readability of the ACT leaflets.

\begin{tabular}{ll}
\hline Test & $\begin{array}{l}\text { No. of } \\
\text { leaflets (\%) }\end{array}$ \\
\hline $\begin{array}{l}\text { Paper type } \\
\text { Glossy }\end{array}$ & $3(6.7)$ \\
Non-glossy & $42(93.3)^{*}$ \\
& \\
Font type size & \\
$<8$ & $19(42.2)$ \\
$\geq 8$ & $26(57.8)$ \\
& \\
Symbols and pictograms & $3(6.7)$ \\
Present & $42(93.3)^{*}$ \\
Absent & \\
& \\
Bilingual information & $31(68.9)^{*}$ \\
English language only & $13(28.9)$ \\
English+ international language & $1(2.2)$ \\
English + local language & \\
*Statistically significant $(p<0.05)$ & \\
& \\
DISCUSSION &
\end{tabular}

The 2008 national demographic and health survey of Nigeria indicates that 44.6 and 57 . $5 \%$ of women (15 - 49 years) and men (15 - 
59 years), respectively, have attained secondary school or tertiary education in Nigeria [13]. This shows that most of the malaria medicine information leaflets are not readable to a majority of Nigerians since majority of the leaflets require a tertiary level of education to appropriately read them. Although most of these leaflets are technical in nature, they appear to be directed to the consumer. Medicine information should be written at a grade level of the intended audience [7]. Health information should be written at SMOG grade of $\leq 5$ [14]. Hence there is need to make malaria medicine information leaflets available in Nigeria more readable to the majority of the population given the fact that in Nigeria these medicines are often obtained over the counter without a prescription. Having readable malaria medicines information leaflets will improve rational use of the drugs in home-based management of malaria. This is because written consumer information has been shown to improve rational use of medicines [15].

The high SMOG grades obtained in this study is as a result of sentence length and high use of medical/pharmaceutical terminology which leads to complex language in information leaflets. Such complex language in information leaflets have been reported to be of concern to consumers [16].

People who have suffered varying degrees of sight loss should be considered when designing medicine information leaflets. A majority of the studied leaflets have very small font size which makes reading difficult, especially for people with impaired sight. Research has also shown that consumers find it difficult to read leaflets with small font size [16]. The reflection of light by glossy papers can make reading difficult [8]. Medicine information leaflets should preferably be produced on uncoated papers to improve readability.

Images in medicines information leaflets aid comprehension of medicine information. A majority of the malaria medicines information leaflets produced in Nigeria did not have symbols and pictograms. Lack of symbols and pictograms can affect consumer's willingness to read and may also limit the understanding of medicine information leaflets. This was demonstrated in a study in which respondents were reported to have criticized poor graphic illustrations in medicine information leaflets [17].

One strategy of making medicine information more readable and useful is by providing them in consumers' primary language [7]. In Nigeria, about 54 and $74 \%$ of men and women, respectively, can read in one of the major languages [9]. A large number of malaria medicine information leaflets in Nigeria were produced in more than one language. However, very few were produced in a major Nigerian language. A majority of bilingual leaflets were in English and French, but only a tiny proportion of Nigerians can read French [18] and this would adversely affect readability.

In view of FMoH's strategy of promoting home management of malaria and rescheduling of ACTs from POMs to OTC medicines, we recommend that pharmaceutical companies should produce readable medicine information leaflets. One way of producing readable consumer medicines information leaflets is by carrying out consumer testing to determine the best design [19]. Furthermore, $\mathrm{FMoH}$ and its regulatory agency, NAFDAC, should also formulate policies that would ensure that manufacturing companies design nontechnical consumer information leaflets as is the practice in some developed countries [16].

\section{Limitations of the Study}

Certain limitations are associated with readability models. For example, they do not consider reader's motivation and familiarity with certain vocabulary and can sometimes overestimate the difficulty of the passage $[5,14]$. Hence a performance-based testing of 
users rather than content-based test (the use of a readability model) would have been a better method of testing the leaflets readability. In addition, since the medicine information leaflets were accessed in a city in Nigeria and considering the huge medicine market in Nigeria, it is possible that some malaria medicine leaflet types were missed by this study.

\section{CONCLUSION}

This study revealed that malaria medicine information leaflets available in the Nigerian market are not readable to the majority of the population. There is need for pharmaceutical companies to produce readable medicine leaflets, given the $\mathrm{FMoH}$ plan to reschedule ACTs from POMs to OTC medicines.

\section{REFERENCES}

1. Federal Ministry of Health. National Antimalarial Treatment Policy. National Malaria and Vector Control Division, Abuja, Nigeria, 2005.

2. Federal Ministry of Health. National strategies and guidelines for home and community management of of malaria. Federal Ministry of Health, Abuja, Nigeria, 2005.

3. Dada OA, Omokhodion FO (2007). Home management of malaria by mothers of children under-5 in Abeokuta, Southwest, Nigeria. Trop Doct, 2007; 37: 217-219.

4. Greer G, Akinpelumi A, Madueke L, Plowman B, Fapohunda B, Tawfik Y, Holmes R, Owor J, Gilpin $U$, Clarence $C$, Lennox B. Improving management of childhood malaria in Nigeria and Uganda by improving practices of patent medicine vendors. Arlington, Va.: BASICS II for the United States Agency for International Development, 2004.

5. Bernard I, Sparks II. Readability of ophthalmic literature. Optomet Vision Sci, 1993; 70(2): 127-130.

6. Macdonald S, McMillan TM, Kerr J. Readability of information leaflets giving to attendees at hospital with a head injury. Emerg Med J., 2010; 27: 279-282.
7. Buck ML. Providing patients with written medication information. Ann Pharmacother., 1998; 32: 962-969.

8. Bradley $B$, Singleton $M$, Po ALW. Readability of patient information leaflets on over-the-counter (OTC) medicines. J Clin Pharm Ther., 1994; 19: 7-15.

9. Basara LR, Juergens JP. Patient package insert readability and design. Am Pharm., 1994; 34(8): 48-53.

10. Chubaty A, Sadowski CA, Carrie AG. Typeface legibility of patient information leaflets intended for community-dwelling seniors. Age Ageing, 2009; 38(4): 441-447.

11. Mansoor LE, Dowse R. Effect of pictograms on readability of patient information material. Ann Pharmacother., 2003; 37(7): 1003-1009.

12. European Commission. Guideline on the readability of the labelling and package leaflet of medicinal product for human use. Brussels, 2009.

13. National Population Commission (NPC) and ICF Macro. Nigeria Demographic and Health Survey 2008. National Population Commission, Abuja, 2009.

14. Smith H, Gooding S, Brown R, Frew A. Evaluation of readability and accuracy of information leaflets in general practice for patients with asthma. BMJ, 1998; 317: 264-265.

15. Nightingale SL. Written patient information on prescription drugs. Int J Technol Assessment Health Care, 1995; 11(3): 399-409.

16. Raynor DK, Blenkinsopp A, Knapp P, Grime J, Nicolson DJ, Pollock K, Dorer G, Gilbody S, Dickinson D, Maule AJ, et al. A systematic review of quantitative and qualitative research on the role and effectiveness of written information available to patients about individual medicines. Health Technol Assess, 2007; 11(5): 1-160.

17. Stichele $\mathrm{RH}$, Van-Heacht $\mathrm{CH}$, Braem MD, Bogaert MG. Attitude of the public towards technical package inserts for medication information in Belgium. Ann Pharmacother., 1991; 25(9): 1002-1006.

18. Sanni DA, Sanni FO. The teaching of the French language in post-primary schools in Nigeria. Sustainable Human Development Review, 2009; 1(1): 55-60.

19. Dickinson D, Raynor DK, Duman M. Patient information leaflets for medicines: Using consumer testing to determine the most effective design. Patient Educ Counselling, 2001; 43: 147-159. 